ISSN: 0212-5099

DOI: https://doi.org/10.24310/BAETICA.2018.v0i38.5511

\title{
LA MONARQUÍA DE FELIPE V Y SUS VÍNCULOS CON LA FRANCIA DE LA REGENCIA: EL CASO DE LA CONJURA DE CELLAMARE
}

\author{
Laia Alonso Armengol* \\ Universitat Autonoma de Barcelona
}

\section{RESUMEN}

En las postrimerías de 1718, se iniciaba un corto conflicto bélico que afectaba directamente a las pretensiones de Felipe V y su corte. Mientras que en la guerra de Sucesión de España, Francia y España formaban un mismo bando, cuatro años más tarde se situaban en posiciones contrapuestas. Uno de los momentos cumbre de este distanciamento es el que ocupa este trabajo; la conspiración de Cellamare o el enésimo intento de injerencia política española en la corte de Versalles. Un episodio que sirve para entender el mismo contexto y el desarrollo de las relaciones franco-españolas.

PALABRAS CLAVE: Cellamare, Versalles, conspiración, equilibrio de poder, guerra de la Cuádruple Alianza

*lalonsoarmengol@gmail.com 


\title{
THE MONARCHY OF PHILIP V AND HIS TIES WITH THE FRANCE OF THE REGENCY: THE CASE OF THE CELLAMARE CONSPIRACY
}

\author{
Laia Alonso Armengol* \\ Universitat Autonoma de Barcelona
}

\begin{abstract}
At the end of 1718, a short war began that directly affected the claims of Felipe V and his court. While in the war of the Spanish Succession, France and Spain formed one side, four years later they were in opposite positions. One of the highlights of this distance is the one that occupies this work; the conspiracy of Cellamare or the umpteenth attempt of Spanish political interference in the court of Versailles. An episode that is useful to understand the same context and the development of Franco-Spanish relations.
\end{abstract}

KEY WORDS: Cellamare, Versailles, conspiration, ballance of power, war of the Quadruple Alliance

*lalonsoarmengol@gmail.com 


\section{INTRODUCCIÓN}

Este trabajo forma parte de una investigación mayor que tiene como objeto de estudio las relaciones franco-españolas después de la Guerra de Sucesión de España y hasta la firma del Tratado de la Haya (1720); entendiendo que hubo cambios sustanciales en dichas relaciones en comparación al periodo anterior. Por lo tanto, intenta matizar la idea perpetuada de que 1700 marcó el inicio de un periodo de entendimiento entre estas dos monarquías, y es que ya durante el mismo conflicto bélico "des tensions fortes marquent cette collaboration diplomatique et militaire"1.

En concreto, este artículo tiene como objetivo explicar las fluctuaciones en las relaciones entre Francia y España a través del caso concreto de la Conjura de Cellamare que se desarrolló en 1718 en Versalles. La perspectiva que se da es básicamente perspectiva española, aunque se intenta puntualizar algunas ideas preestablecidas sobre este hecho histórico. La relevancia de este no se halla en la misma estrategia política de la conspiración, sino como caso paradigmático que ejemplifica los mecanismos diplomáticos de la época y como se traducía esto en formas concretas de establecer vínculos entre estados. De este modo, el estudio de la conspiración de Cellamare quiere ser una herramienta de conexión entre dichas cortes y sus relaciones dentro de un periodo concreto como fue el Revisionismo de Utrecht, el cuál sirve de marco cronológico amplio.

En definitiva, el propósito principal no es hacer una descripción simple de los hechos acontecidos, sino ahondar en las relaciones, motivos y consecuencias de este suceso infiriéndolo en un contexto concreto. De este modo, quiero enfatizar en todo aquello que pudo llevar a esta injerencia, así como los vínculos transnacionales que unían ambas cortes siendo consciente de las fluctuaciones, los intereses y la acción tanto de los monarcas como de los ministros, siendo uno de los protagonistas el cardenal Alberoni.

Finalmente, el trabajo da básicamente la perspectiva española fruto de las fuentes documentales usadas: correspondencia, relaciones de hechos y otros documentos del mismo Felipe V o sus ministros como Alberoni, Grimaldo o el príncipe de Cellamare. También me he servido de las copias de los tratados de la época tanto los que ponían fin al conflicto sucesorio (Utrecht, Rastatt y Baden), los que querían mantener el estatus salido de este (Triple y Cuádruple Alianza), así como el que ponía fin a la guerra de la Cuádruple Alianza (firmado en la Haya en 1720). La mayor parte de

1. L. BÉLY (2013), 62.

(C) Baetica. Estudios Historia Moderna y Contemporánea, 38, 2018, 135-157. Facultad de Filosofía y Letras, Universidad de Málaga. Departamento de Historia Moderna y Contemporánea 
esta documentación de cariz político y diplomático se encuentra en el Archivo Histórico Nacional, el Archivo General de Simancas y la Biblioteca Nacional de España.

\section{EL REVISIONISMO DE UTRECHT Y EL CONTEXTO EUROPEO DESPUÉS DE LA GUERRA DE SUCESIÓN DE ESPAÑA}

El objeto de estudio de este trabajo es la Conjura de Cellamare, aun así este suceso parece indisociable de unos antecedentes más o menos lejanos que explican los motivos y la forma que toma este intento de injerencia política. De hecho, debemos trasladarnos a los últimos coletazos del conflicto sucesorio español y la firma de los distintos tratados que lo cerraron; vastamente estudiados, por otra parte.

Es sabido que "la muerte de Carlos II [...] desencadenó una guerra internacional en la que las potencias europeas se disputaron el control del comercio colonial y la hegemonía continental”2, por lo que tuvo tintes políticos, económicos, sociales e, incluso, culturales que iban más allá de las razones dinásticas. Por su parte, una de las temáticas más explotadas, dentro de este marco cronológico, han sido las relaciones entre Francia y España, por el interés que suscita la formación del frente común bajo el manto Borbón; algo que parecía una novedad puesto que Francia había sido "l'ennemi natural des deux siècles précédents" . Para entender este acercamiento debemos fijarnos en el mismo cambio dinástico en España y la proclamación del nieto de Luis XIV, Felipe V, como nuevo monarca español. A pesar de su avanzada edad y reinado longevo, el monarca francés seguía monopolizando el juego diplomático europeo e intentando reforzar su posición en el tablero.

Este frente franco-español no sólo tuvo una traducción fáctica a nivel bélico, sino también en la política interna, básicamente, hispánica. En un primer momento, los intentos de Luis XIV por gobernar el otro lado de los Pirineos, a través del control del espacio cortesano y personajes como la princesa de los Ursinos u Orry ${ }^{4}$. Más adelante, y junto con el desarrollo

2. J. Albareda Salvadó (2007), 271.

3. M. V. López-Cordón Cortezo (2003), 185.

4. Esta influencia francesa queda demostrada parcialmente en este fragmento de una misiva de Felipe V a su abuelo: "hace ya demasiado tiempo que tengo mi corazón oprimido por no abrirlo a vuestra majestad como un nieto a un abuelo que le ha testimoniado siempre tantas bondades. Podéis estar seguro de que aquí están mis verdaderos sentimientos [...], porque nadie, ni siquiera la Reina, la princesa de los Ursinos u Orry saben 
del conflicto, hubo un distanciamiento de una monarquía y la otra, fruto de distintos choques a lo largo de la contienda y, sobre todo, con el fin de ella ${ }^{5}$.

Una estrecha unión era necesaria para el bien de Francia y España, pero sin presentar ninguna clase de dependencia por parte de la segunda. Cada reino debía erigirse según sus costumbres y sus máximas. Y aunque el rey pudiera arreglar todos los asuntos de España, no le convendría encargarse de ellos. Eso sería fortalecer inútilmente los celos de las principales potencias europeas, que considerarían a España como sometida a sus órdenes. [Aun así,] las muestras de unión y confianza absoluta eran necesarias para la obtención de la paz ${ }^{6}$.

Un cambio que parecía evidente ya en octubre de 1711 e inicios 1712 cuando se iniciaban las negociaciones franco-británicas ${ }^{7}$ y las conversaciones para los tratados de Utrecht, respectivamente ${ }^{8}$. Siendo Luis XIV el responsable de dirigir dichos contactos marcando unas líneas de acuerdo alejadas de los objetivos de Felipe V de España, como evidencia el paradigmático caso catalán o el dominio comercial, tal y como advierte Bély:

alors que la Cour de Madrid semble suivre en aveugle les décisions prises à Versailles, dans la réalité, des tensions fortes marquent cette collaboration diplomatique et militaire. Les réticences de l'administration espagnole visà-vis des injonctions françaises s'imposent en particulier dans le domaine commercial ${ }^{9}$.

Disputas no poco importantes puesto que se acaban materializando en los acuerdos de Utrecht (11 de abril de 1713), Rastatt (7 de marzo de 1714) y Baden (7 de septiembre de 1714), que a su vez se convierten en

que os envío esta misiva, pero lo hago por que tengo una confianza plena en vuestra ternura [...] y sé que tendréis a bien arrancarme del pesar que me aflige”, Carta de la mano de Felipe V a Luis XIV, Madrid, 8 de febrero de 1704, en J.M. Bernardo Ares; E. Echeverría Pereda y E. Ortega Arjonilla (2011), 211.

5. "Los últimos meses del reinado de Luis XIV son una muestra más del difícil encaje entre los intereses del rey de Francia y su nieto” en N. Sallés Vilaseca (2016), 321

6. A. BAudrillart, (2001), 396.

7. Los intereses de la Gran Bretaña estaban centrados en la obtención de beneficios comerciales, por lo que llegó plantear que Luis XIV se uniese a su alianza en contra de España en las negociciones de Gertruydenberg (1710), J. Albareda Salvadó (2015), 67-68.

8. L. BÉLy (2007), 646.

9. L. BéLy (2015), 62.

(C) Baetica. Estudios Historia Moderna y Contemporánea, 38, 2018, 135-157. Facultad de Filosofía y Letras, Universidad de Málaga. Departamento de Historia Moderna y Contemporánea 
la base para entender el nuevo escenario internacional salido del fin de la contienda. Sobre todo, el de Utrecht entendido como un conjunto de tratados bilaterales entre estados europeos como Gran Bretaña, Francia, España, las Provincias Unidas, Saboya, Portugal y Prusia. Por lo tanto, estos tratados abarcan una multiplicidad de temáticas que desbordan los límites de este trabajo; aun así, el caso español es paradigmático puesto que "jamás una monarquía ha sufrido un desmembramiento como los [...que] tuvo que soportar [España] en Utrecht” ${ }^{10}$, cosa que no le pasó a Francia que incluso salió favorecida y fortalecida, en términos generales.

En primer lugar, por lo que respecta a los aspectos territoriales, España fue desmembrada del que había sido su imperio. Víctor Amadeo de Saboya recibía Sicilia ${ }^{11}$; Carlos VI de Austria recibía territorios en la península Itálica (Milán, presidios de la Toscana o Nápoles), Cerdeña, los Países Bajos Españoles, Luxemburgo y otras ciudades francesas (Ypres o Tournai) ${ }^{12}$; por su parte Gran Bretaña obtenía Gibraltar y Menorca; y Francia territorios básicamente americanos. Este desmembramiento no se hizo sin los intentos de resistencia de Felipe $\mathrm{V}$ quien tenía claro que la prioridad era la unidad peninsular y el dominio americano ${ }^{13}$, pero con la máxima de conservar todo lo que se pudiese la cual se convirtió en intentos violentos para recuperar cierto estatus territorial y político.

En segundo lugar, los aspectos comerciales de los que se benefició especialmente la Gran Bretaña a través del navío de permiso y el asiento de negros. Por último, la renuncia de Felipe $\mathrm{V}$ a sus derechos al trono francés, lo que supondrá un fracaso explícito del frente franco-español puesto que el conflicto se había iniciado por la negativa a dicha renuncia. De hecho, este punto de los acuerdos tendrá relevancia en la Guerra de la Cuádruple Alianza y el consiguiente Tratado de la Haya.

Lo importante de las negociaciones y acuerdos son los intentos de Luis XIV para que su nieto aceptase sus directrices; así como la distancia que hubo entre estas y las instrucciones de Felipe $\mathrm{V}$ a sus plenipotenciarios. 45 puntos en las que se expresa la preocupación por la unidad de la monarquía y la jerarquía de territorios ante una posible pérdida, las posibles concesiones comerciales o la inmovilidad frente al caso catalán. Un distan-

10. J. Albareda Salvadó (2015), 67-68.

11. Esta operación se hizo por interés expreso de Gran Bretaña, L. BéLy (2007), 647.

12. J. Albareda Salvadó (2015), 66.

13. Archivo Histórico Nacional (AHN), Estado (ES), n. ${ }^{\circ} 3376-2$, fol. 10. Documentación sobre las negociaciones de Utrecht que llega a Madrid, 28 de diciembre de 1711. 
ciamiento fraternal que benefició el acercamiento de Francia al Emperador como demuestran los tratados de Rastatt y Baden, el tratado de evacuación de Cataluña (1713) o el empeño en obtener la paz entre España y Austria proponiendo nuevas condiciones ${ }^{14}$.

Con el fin de la contienda y la firma de dichos tratados, se abre un nuevo periodo denominado Revisionismo de Utrecht que se alarga hasta 1748 y la guerra de Sucesión de Austria; un lapso temporal en el que las relaciones internacionales están sujetas al escenario salido de Utrecht ${ }^{15}$. Un periodo marcado por "intensas negociaciones, a menudo secretas, teniendo en cuenta la complejidad de los intereses" ${ }^{16}$ lo que explica que en bastantes años no se produzca ningún gran conflicto y se tienda al equilibrio europeo, concepto básico para descifrar dichas relaciones entre estados. Aun así, no se escapa de la lógica de las hegemonías recayendo en este momento sobre Gran Bretaña y Francia.

No es menos cierto que ya en los primeros años de este nuevo periodo se hacen visibles las heridas abiertas, especialmente de Felipe V quien no acepta su nueva situación lo que le lleva a desarrollar una política exterior más agresiva, siendo un ejemplo de ello la Conjura de Cellamare.

\section{LAS RELACIONES FRANCOESPAÑOLAS ENTRE 1715 Y EL INICIO DEL CONFLICTO DE LA CUÁDRUPLE ALIANZA}

\subsection{Del fin de la guerra a los tratados entre Francia y Gran Bretaña}

El fin de la contienda evidenció otros cambios en la política interior de distintos estados europeos. El fin de la larga vida de Luis XIV en septiembre de 1715; el cambio dinástico en Gran Bretaña con el advenimiento de los Hannover; o el nuevo matrimonio de Felipe V con Isabel de Farnesio ${ }^{17}$. La llegada de esta reina parmesana condicionó el gobierno y la corte de

14. Archivo General de Simancas (AGS), Estado (ES), n. ${ }^{\circ}$ 8128, s. f. Condiciones de Luis XIV para la paz con la casa de Austria y el Imperio, 2 de abril de 1713.

15. Uno de los puntos para tener en cuenta en este periodo es la sucesión de Carlos VI, su descendencia femenina marcará el desarrollo de sus intereses a través de la Pragmática Sanción, en M. S. ANDERSON (2014), 7.

16. L. BÉLY (2015), 63.

17. Una mujer que "habría querido gobernar al mundo entero [...], hacia la realización de sus propósitos”; frase atribuida a Federico II de Prusia, en M. Á. Pérez SAmper (2003), 103. 
Madrid con la llegada y pujanza de nuevas personalidades, siendo el cardenal Alberoni el caso paradigmático ${ }^{18}$.

Por su parte, la muerte del rey Sol significó el acceso al trono de Luis $\mathrm{XV}$, el biznieto de 5 años del anterior monarca y huérfano de padre y madre ${ }^{19}$; con ello, la lucha por el acceso al poder y la necesidad de establecer una regencia. En este contexto, Felipe V defiende el deseo de su abuelo de mantener la paz de "dos naciones que [...] no harán en adelante más de un solo pueblo"20, con el claro objetivo de erigirse como protector del nuevo monarca francés, en sus palabras: "de cuya autoridad me tocaba como de la línea recta reinante”21. Enfrente de las pretensiones de Felipe V se encontraba Felipe de Orleans, sobrino de Luis XIV casado con una hija legitimada del mismo, Madmoiselle de Blois. Sea como sea, ambos tenían motivos familiares para legitimar su postura y querían imponer su posición frente al otro ${ }^{22}$. Aun así, era Felipe de Orleans el que tenía más posibilidades como demuestran las palabras de Luis XIV que iban dirigidas a este:

aunque podía imitarle en todas sus acciones, pero que lo dejase hacer acerca de la guerra, que lo excusase todo lo posible, y que toda mira la pusiese en mantener a su reino y su pueblo en una tranquila paz. [...] Aunque vuestros émulos han pretendido muchas veces, poner mal vuestro honor con mi estimación, con todo siempre os he conservador un íntimo y entrañable amor, el que conoceréis, si faltara el delfín (lo que Dios no permita) [...] lo habréis adelantado para vos mismo ${ }^{23}$.

18. Este había tenido un papel principal en la elección de la nueva reina, así como de los cambios internos en la corte española y la defenestración de aquellos que habían conformado el gabinete francófilo. Ejemplo de ello Melchor de Macanaz y la belicosidad en sus escritos en contra Alberoni; en Biblioteca Nacional de España (BNE), Manuscritos (Mss.), n. ${ }^{\circ}$ 7397. Disertación de Melchor de Macanaz sobre el ministerio de Cardenal Alberoni, 1720.

19. É. Bourgeois (1909), 1.

20. BNE, 2/52217(10), fol. 1. Impreso propagandístico de Felipe V sobre los motivos por los que España no se adhirió al tratado de la Triple Alianza, Madrid, 20 de febrero de 1719.

21. Ibidem, fol. 7.

22. Una relación que ya se planteba difícil desde los años de contienda con la detención de Felipe de Orleans en Segovia, en A. Baudrillart (2001), 515-518. El duque de Orleans había tenido un papel destacable en el conflicto como demuestra la correspondencia de este durante su paso por la Corona de Aragón en 1707 (AHN, ES, n. ${ }^{\circ}$ 2454, 1-54).

23. BNE, U/9819, fols. 1-2. Relación de hechos de los últimos días de vida de Luis XIV, 1715. 
Esta intención se descubriría ya en el testamento en el que se estipularía una regencia repartida entre, básicamente el duque de Orleans, quien tendría la gobernación del reino junto con un consejo formado por príncipes de sangre y mariscales como Villars o Huxelles. Por su parte, la tutela quedaba bajo el duque de Maine. Quedaba excluido Felipe V por voluntad expresa de Luis XIV, posiblemente como mecanismo para preservar la paz exterior de Francia.

Este proceso no estuvo exento de intrigas; por un lado, la operación del duque de Orleans para obtener una regencia unipersonal, que consigue gracias al consentimiento unánime del Parlamento de París ${ }^{24}$. En la práctica, las voluntades de Luis XIV no se cumplían de forma rigurosa con la reacción obvia de aquellos que se veían perjudicados por este incumplimiento. El mismo duque de Maine declaró “le duc d’Orleans n’est pas blessé du choix ma personne pour l'honorable employ auquel je suis appellé”25, esto supone en parte una dislocación de lo que tenía que suponer la política francesa después de Utrecht, según el mismo Luis XIV. Aun así, esto benefició los intereses de Jorge I de Hannover quien tenía un especial interés en esta regencia y en una posible influencia sobre el trono francés, a través del embajador Stairs ${ }^{26}$.

Por su parte, en Madrid también interesaba esta regencia por las pretensiones de Felipe $\mathrm{V}$ ya apuntadas. Esto se demuestra con una intensa correspondencia desde dicha ciudad, normalmente revisada por el marqués de Grimaldo, al príncipe de Cellamare, el nuevo embajador en París desde su nombramiento a inicios de 1715.

Antonio del Giudice ${ }^{27}$ o príncipe de Cellamare y duque de Giovinazzo (Nápoles, 1657-Sevilla, 1733) era hijo de una familia noble de origen genovés que había entrado al servicio de la monarquía bajo el reinado de Carlos II. Como era común en el caso de los embajadores, llegó a París con numerosas pautas que debía seguir en la nueva corte, las cuales fueron renovándose y redefiniéndose con los años. En estas instrucciones de Felipe V cristaliza este interés por establecer una regencia pro-española

24. BNE, U/9819, fols. 5-6.

25. AHN, ES, n. ${ }^{\circ}$ 3978, s. f. Acta del Parlamento francés sobre la apertura del testamento de Luis XIV y las reacciones de los cortesanos, París, 10 de septiembre de 1715.

26. É. Bourgeois (1909), 36.

27. Destaca sus vínculos sanguíneos con Francesco del Giudice, muy influyente en la corte e Inquisidor General que cayó en desgracia en 1716-17, aunque esto no afectó a Cellamare que se había ganado la confianza de Alberoni. D. Ozanam (2002), 587. 
defendiendo sus derechos, o los de sus hijos, sobre el trono francés, incluso antes de la muerte del mismo Luis XIV ${ }^{28}$.

Bien es cierto que, por los tratados de Utrecht, Felipe V había renunciado a sus propios derechos, pero cabía la posibilidad tanto de reclamarlos para sus hijos, como de establecer una influencia sobre la corte versallesca, recordando la obsesión de su abuelo para unir a las dos coronas Borbón ${ }^{29}$. De todos modos, parece una perspectiva naif puesto que una operación de esta magnitud habría desequilibrado el mapa europeo con el consecuente recelo de los estados europeos.

Sea como sea, las instrucciones al príncipe de Cellamare eran suficientemente elocuentes: era necesario obtener una buena posición en la tutela del futuro rey y, en el caso que el testamento de Luis XIV no fuese favorable, Cellamare debía formar un partido pro-español. Felipe V hace una relación de personalidades y la posibilidad, o no, de mantener una colaboración con ellas; madame de Montespan, de quien se podía obtener información, o el conde de Toulouse, quien serviría para llegar a los duques de Maine o la casa de Condé y Conti. Gran parte de estos, hijos legitimados de Luis XIV y madame de Montespan que habían adquirido el estatus de príncipes de sangre.

Por otro lado, también habla de otras personalidades y casas nobiliarias; algunos con los que mantener una relación favorable, como el padre confesor Le Tellier, y otros con los que establecer un régimen de vigilancia, como el duque de Orleans evidenciando la tensión existente fruto del objetivo común que compartían. Por encima de todo, la figura del ministro marqués de Torcy, muy próximo a la corte española, con el que se contaba especialmente para obtener información relevante; ya sea sobre la regencia, los contactos para una paz entre España y Austria, movimientos diplomáticos de otros estados europeos o disposiciones para la ayuda a Jacobo Estuardo.

28. Felipe V declaraba en estas instrucciones al príncipe de Cellamare: "respecto a la situación en que presentamente se haya la Francia, a la crecida edad de Su Majestad Cristianísima y la tierna del Delfín [...] es de considerar mi derecho a la tutela de aquel pequeño príncipe como pariente más cercano y en tal forma se asienta disponer las leyes de aquel reino, con que como sea entendido parece que ella pueda derogarse por el rey. Es en este suposición y en la de haber hecho el testamento y entregado cerrado al Parlamento de París, debe creerse no tal solamente arreglado este punto [...] posibilitado a ejercer por mi persona este encargo". AHN, ES, n. ${ }^{\circ} 3494$, fol. 4. Instrucción diplomática de Felipe $\mathrm{V}$ al príncipe de Cellamare para el empleo de embajador ordinario en la corte de Luis XIV, 1715.

29. J. M. Bernardo Ares (2009), 131. 
La creación de este partido español permite entender la manera como se desarrolla la conjura de Cellamare de 1718, puesto que aquí nace la colaboración entre este embajador y algunos personajes del entorno de Luis XIV descontentos con las disposiciones de la nueva regencia. Por lo tanto, se trata de una red diplomática multidireccional en la que se sirven unos de otros, según los intereses particulares de cada uno.

\subsection{Los tratados de la Triple y Cuádruple Alianza y las empresas españolas en la península Itálica}

Con el fracaso de toda tentativa española en la regencia francesa, se inicia el ejercicio de gobierno del duque de Orleans junto al abate Dubois. Un tandem que significaría el claro acercamiento francés a la Gran Bretaña de Jorge I y Stanhope ${ }^{30}$. Estos dos ministros serían de especial relevancia para la formulación de los tratados de la Triple Alianza (1717) y de la Cuádruple Alianza (1718) que determinarían el desarrollo de los acontecimientos posteriores ${ }^{31}$.

Unos tratados que chocarían con los distintos intentos de España para recuperar el estatus perdido entre 1713 y 1714. Estos eran suscitados por el interés de los monarcas y los ministros preeminentes como Alberoni, cuya relevancia política ya había sido observada por el embajador francés en Madrid, el marqués de Saint-Aignan que tenía como objetivo la defenestración de este. Esto evidencia las distintas injerencias políticas entre ambas monarquías para buscar líneas políticas que beneficiaran a los propios intereses.

El tratado de la Triple Alianza nace en un momento en el que Francia y Gran Bretaña, estados que habían salido victoriosos del conflicto sucesorio, pero que necesitaban reforzarse debido a los cambios internos que habían sufrido:

durante estos dos años (1716-1717) [...] tuvo lugar un verdadero despliegue de presión diplomática tanto de los británicos como de los franceses para

30. "Stanhope era un embajador de Inglaterra. Llevaba en España mucho tiempo, en dos etapas [...]. Era un perfecto inglés. Culto, enamorado de sus libros y del estudio de las ciencias abstractas, versado en historia, muy al tanto de los intereses de su nación y de pormenores de su corte y del parlamento inglés, [...] conocedor profundo de la corte del país, del comercio español, de los intereses generales y particulares de la nación en la que residía”. SAINT-Simon (2008), 305.

31. N. Sallés Vilaseca (2016), 434-435. 
incluir las cláusulas de garantía en prácticamente todas las negociaciones bilaterales en curso, cuyo esfuerzo nos revela la profunda incertidumbre que causaba en el ánimo de Felipe de Orleans y de Jorge I [de Gran Bretaña] el conflicto aún no cerrado entre Felipe V y Carlos $\mathrm{VI}^{32}$.

Se conforma un movimiento cuadricular entre Francia, España, Gran Bretaña y Austria. En primer lugar, una relación ambivalente entre Felipe V y Jorge I, puesto que este primero tiene un especial interés en ayudar al conflicto jacobita en contra de los Hannover ${ }^{33}$, pero al mismo tiempo busca tratados con este segundo que acaban en pequeños acuerdos comerciales sin contenido político. En segundo lugar, el emperador Carlos que conseguía un acuerdo con Gran Bretaña de defensa mutua en 1716. Por último, Francia que mantiene relevantes contactos con Gran Bretaña a través del tándem Dubois-Stanhope, quienes preparan unos acuerdos sobre la base de Utrecht. El compromiso mutuo de que se mantuviera el espíritu de Utrecht o lo que es lo mismo, su papel como mediadores y potencias hegemónicas.

Así se firmaba el tratado de la Triple Alianza el 4 de febrero de 1717 entre Francia, Gran Bretaña y las Provincias Unidas, el cual tenía como objetivo el mantenimiento de la paz establecida en Utrecht en abril de 1713, tanto a nivel europeo como colonial. En la práctica esto significaba el rechazo a cualquier intento español de querer romper con lo establecido, el compromiso de respetar la línea reinante protestante en Gran Bretaña y el gobierno formado en Francia para la regencia de Luis XV.

Felipe $\mathrm{V}$ en este contexto tenía otros planes para su monarquía como se vio en verano del mismo año y es que, bajo su punto de vista, las negociaciones de la Triple Alianza debían servir para reorganizar a su favor el territorio italiano: tanto aquellos perdidos como aquellos sobre los cuales tenían derechos de sucesión sus hijos (Parma, Plasencia y

32. N. Sallés Vilaseca (2015), 284.

33. Durante 1715 se prepara una empresa para prestar ayuda al conflicto que se da en Escocia; el príncipe de Cellamare informa periódicamente del desarrollo de esta y de una posible colaboración francesa que no se acaba dando. Aun así, la ayuda que se pudo dar no fue determinante, aunque era una baza útil para Felipe V que usará también en 1719 con la organización de una flota fracasada. AHN, ES, n. ${ }^{\circ} 3494$. Carta de Felipe V al príncipe de Cellamare sobre las instrucciones para apoyar al pretendiente jacobita, 16 de septiembre de 1715 . 
Toscana) ${ }^{34}$. Es por eso que se organizó y realizó la ocupación de Cerdeña, aprovechando la cruzada contra el Turco; esta se hizo junto con el Papado ${ }^{35}$ y servía para despistar a un Emperador ocupado también en su particular conflicto contra el Turco en Hungría ${ }^{36}$.

Esta empresa en Cerdeña es un éxito para los españoles ocupando toda la isla y poniendo en jaque el tratado de la Triple Alianza firmado meses antes. Aun así, no hubo una respuesta inmediata y se esperó al siguiente movimiento para reaccionar. Este se dio al verano siguiente con la ocupación de Sicilia, una flota de 340 embarcaciones y 30000 hombres que había zarpado de Barcelona el 18 de junio de 1718 y había llegado a Messina el 4 de julio, bajo las órdenes del marqués de Lede ${ }^{37}$.

La preocupación era evidente materializándose en la firma del tratado de la Cuádruple Alianza el 2 de agosto de 1718 que, a la práctica, significaba la ratificación del anterior, pero con la unión de Carlos VI a los acuerdos. Al Emperador se le aseguraba, con el fin de la "conservación de la Paz" ${ }^{38}$ su presencia en Sicilia, que por los tratados de Utrecht había quedado bajo gobierno de Víctor Amadeo de Saboya. Además, también pasaban a feudo imperial el Gran Ducado de la Toscana y el ducado de Parma y Piacenza, que habían estado en manos de la familia Farnesio. Aun así, se estipulaba la posibilidad de que pasase a un hijo de Isabel de Farnesio y Felipe V si no había descendencia masculina en el territorio ${ }^{39}$.

34. N. SAlLÉs, (2016a), 317.

35. Las relaciones entre España y el Papado no habían sido buenas desde 1709 cuando se habían roto las relaciones entre ambos. La llegada de Alberoni y el cambio en ciertas políticas regalistas, propiciaron el inicio en París de las conversaciones para llegar al concordato de 1717. Fue un acuerdo provisional pero sirvió para llegar a cierto apaciguamiento que llevó a formar una empresa conjunta contra el Turco, oportunista por parte de Felipe V. En M. G. Aparicio Valero (2013), 128. y T. Egido (1979), 175.

36. "quien pudiera imaginarse, que un Príncipe [...] hubiera querido emprender una hostilidad [...] contra el Archiduque, al tiempo que está [en...] guerra contra el Turco". Biblioteca Real (BR), II/1431-1433, fol. 2. Carta del marqués de Grimaldo al príncipe de Cellamare sobre la empresa de Cerdeña, julio de 1717.

37. C. Martínez Shaw y M. Alfonso Mola (2001), p.260.

38. BNE, VE/309/30, fol. 41.

39. L. BÉLY (2015), 49.

(C) Baetica. Estudios Historia Moderna y Contemporánea, 38, 2018, 135-157. Facultad de Filosofía y Letras, Universidad de Málaga. Departamento de Historia Moderna y Contemporánea 


\section{LA CONJURA DEL EMBAJADOR CELLAMARE Y EL PARTIDO ESPAÑOL EN VERSALLES}

\subsection{El desarrollo de la Conjura de Cellamare}

En verano de 1718, las relaciones entre Francia y España eran complejas por la contraposición de los intereses de ambos; el primero quería mantener su posición hegemónica junto a Gran Bretaña y, por su parte, el segundo buscaba reformular los acuerdos de Utrecht para recuperar su posición. Aun así, ni mucho menos se habían roto las conversaciones y los intentos de injerencia seguían siendo relevantes a banda y banda de los Pirineos. El caso paradigmático de esto es la conjura de Cellamare que se desarrolló en otoño e invierno de 1718.

El objetivo de esta conspiración era acabar con la regencia de Felipe de Orleans, el regente de Luis XV de Francia, y establecer una línea de gobierno favorable a los intereses españoles. Felipe $\mathrm{V}$ entendía, como ya se ha apuntado anteriormente, que esa posición le correspondía, sabiendo de la importancia del dominio político de Versalles. Del mismo modo, esto es fácilmente relacionable con el lustro en el que fue Luis XIV quien influyó sobre la política española a través de ministros y cortesanos como Amelot, Orry o la princesa de los Ursinos ${ }^{40}$.

La organización de la trama no era ni mucho menos compleja y su fin maximalista difícil de alcanzar. De hecho, la relevancia de este suceso no es la misma forma de la conspiración, sino sus consecuencias y como ejemplo que contribuye a explicar un contexto histórico concreto en relación con las relaciones franco-españolas.

La conjura de Cellamare no puede disociarse de la formación del partido español en Versalles ya en 1715 puesto que es una continuación de esta. Este embajador se había aprovechado de las enemistades cosechadas por el regente para formar este círculo, contrario a la regencia del duque de Orleans por múltiples motivos. Ya en las instrucciones de Felipe V podían intuirse aquellos que podían formar parte de este partido, y por tanto de la conspiración. De hecho, no le fue difícil al príncipe de Cellamare encontrar a dichas personas como Madame de Maintenon, el conde de Toulouse, el príncipe de Conti, el ministro Torcy o el confesor Le Tellier. Estas ene-

40. A. Baudrillart, (2001), 199. 
mistades entre distintos sectores de la corte francesa quedan parcialmente ejemplificadas en la correspondencia de Cellamare:

no está menos enconada la disensión que ya había entre el señor príncipe de Conti y el caballero de Rohan, la que ahora se ha renovado pues hallándose Su Alteza en un aposento [...] y habiendo concurrido el caballero de Rohan en el mismo paraje, le dijo alguna aspereza [diciendo al] príncipe se apartase de su presencia [...] dando las más claras muestras de un grave resentimiento ${ }^{41}$.

Uno de los problemas principales fue el conflicto abierto entre los príncipes legítimos y los legitimados (duque de Maine, conde de Toulouse y princesa de Condé); la raíz del conflicto tenía un carácter político por los derechos y estatus de estos príncipes. Bajo el reinado de Luis XIV, los hijos legitimados habían sido designados príncipes de sangre y en este momento, bajo la demanda de los hijos legítimos, habían sido degradados a pares de Francia en un conflicto que acababa en 1717 como demuestra este fragmento:

ahora quedamos solo con la expectación de cómo se gobernarán los príncipes legitimados hallándose derribados, y desposeídos de la elevación en que el difunto monarca les había puesto, pues aún pudieran empeorar la condición y aventurar el perderse, si no manifiestan la conveniente resignación, conformidad ${ }^{42}$.

Por tanto, el desarrollo de esta conjura se aprovechaba de la situación de cierta inestabilidad interna en Francia que estaba afectando a las decisiones externas, dando cierta imagen de crisis política de la regencia ${ }^{43}$. No es de extrañar que los protagonistas de esta conjura fueran, aparte del príncipe de Cellamare, el duque y duquesa de Maine, de la casa Borbón-Condé, la princesa de Condé o el diplomático Polignac. La primera casada con el duque de Maine que, aparte de perder el estatus de príncipe de sangre, ya en 1715 había visto reducido su papel en la política francesa. Este había sido designado por el testamento de Luis XIV como tutor del joven monarca, pero fue apartado por el duque de Orleans quien ejerció la regencia de forma unipersonal. Por lo tanto, ambas partes, la francesa y la española, formaron un grupúsculo

41. AGS, ES, n. ${ }^{\circ}$ 4326, s. f. Carta del príncipe de Cellamare desde París al marqués de Grimaldo sobre las nuevas de la corte francesa, 1 de marzo de 1717.

42. AGS, ES, n. ${ }^{\circ}$ 4326, s. f. Carta del príncipe de Cellamare desde París al marqués de Grimaldo sobre el conflicto entre los príncipes franceses legítimos y los legitimados, 5-9 de julio de 1717.

43. N. Sallés Vilaseca (2015), 301. 
caracterizado por unas relaciones multidireccionales y motivos múltiples sirviéndose unos de otros para alcanzar un objetivo común.

Esta finalidad debía alcanzarse a través de una estrategia fácilmente averiguable a través de un dossier de Cellamare con varios documentos que comprometían esta conspiración. Por una parte, mensajes que debían llegar a los Parlamentos y Estados Generales, junto con una petición al rey para la convocatoria de estos y un documento por el cual se ofrecía la regencia a Felipe V. Así pues, el partido español pretendía forzar la convocatoria de los Estados Generales con el objetivo de presentar una propuesta de una nueva regencia, dejando en manos de los estamentos decidirlo. Probablemente, los conspiradores se habrían asegurado de que la respuesta fuese favorable a sus intereses; aunque esto muestra la dificultad de una maniobra incompleta. Lo que se conoce de esta conjura deja muchos cabos sueltos, sobre todo en relación con el papel que desarrollaba cada individuo en esta red diplomática y clientelar; de hecho, cabe preguntarse hasta qué punto la responsabilidad máxima era del príncipe de Cellamare. Aun así, el fracaso de esta conspiración no fue por la misma naturaleza de esta, sino por el descubrimiento por parte de Felipe de Orleans.

Toda esta información sin cifrar que había recogido Cellamare tenía que llegar a Madrid a través del abate Portocarrero que acompañaba al hijo del embajador en Inglaterra Monteleón. Aun así, alguna información de más dada por un copista español alertó al regente de la existencia de este paquete sospechoso entre el equipaje de estos dos personajes. Efectivamente, el 5 de diciembre de 1718 fueron detenidos en Poitiers y descubiertos estos documentos que revelaban "una conspiración esbozada por el duque, hijo legitimado de Luis XIV, y la duquesa [...], así como los nostálgicos de la vieja corte" ${ }^{44}$, junto con otros políticos españoles, el príncipe de Cellamare entre ellos. Pero por encima de este, el cardenal Alberoni conocido por su "línea política audaz [...que buscaba] una nueva presencia española en Europa”45.

La respuesta desde el gobierno de la Regencia fue el de detener y encarcelar a todos los príncipes y ministros que habían sido identificados en esta trama, aunque se les perdonó al poco tiempo, incluso a los duques de Maine. Por su parte, el príncipe de Cellamare fue expulsado de Francia y, por tanto, relevado de su cargo como embajador en Versalles: "Sa Majesté a pris la resolution le 9 du present mois, de renvoyer [...] l'Ambassadeur du Roy d'Espagne, et d'ordonner du'un gentil-homme [...] l'accompagne

44. L. BÉLy (2015), 52.

45. Ibidem, 46. 
jusqu'à la Frontiere d'Espagne”"46. Es así como acababa este intento de injerencia española en la política francesa y la trayectoria de Del Giudice en París, aunque siguió su servicio a la monarquía de Felipe V hasta su muerte en 1733. De hecho, su cargo como embajador no fue suplido hasta 1720 por Patricio Laules, fruto del cierre en las relaciones entre ambas monarquías en el contexto de conflicto bélico que se iniciaría poco después del descubrimiento de esta conjura.

En definitiva, el desarrollo de esta conspiración en Versalles no se caracterizó por ser muy compleja ni mucho menos fructífera. Aun así, nace de una red de relaciones cortesanas y diplomáticas entre agentes muy distintos ${ }^{47}$, pero con algún tipo de aversión al regente francés. O, mejor dicho, personas que habían perdidos privilegios, o la posibilidad de tenerlos: la duquesa de Maine, Felipe V, Cellamare, Alberoni o, incluso, el exiliado Melchor de Macanaz.

De hecho, podemos sistematizar algunos grupos dentro de esta red, según su participación en la conjura. En primer lugar, aquellos que no desarrollaban su actividad desde Versalles. Por una parte, Alberoni y Felipe V, desde la corte de Madrid, plantearon los objetivos y las aspiraciones, pero no mantuvieron los contactos directamente ni la organizaron de forma activa ni directa. Aun así, no deja de ser relevante ni mucho menos, además teniendo en cuenta que uno de ellos es el mismo monarca, de quien depende el gobierno, y el otro el que era considerado el ministro que dirigía todas las operaciones ${ }^{48}$. Por otra parte, es destacable la participación de Melchor de Macanaz, quien desde su exilio en Pau continuaba intentando tener un papel en la política española ${ }^{49}$. Según su propio testimonio, estuvo en sus manos el contacto con los Estados Generales para el desarrollo de la conspiración y la elección de Felipe V como monarca ${ }^{50}$.

46. AHN, ES, n. ${ }^{\circ} 2819$, s. f. Impreso propagandístico francés sobre las decisiones tomadas a raíz del descubrimiento de la conjura de Cellamare, 9 de enero de 1719.

47. A. Baudrillart, (2001), 522-523.

48. Esto se puede comprobar por la obsesión tanto de Gran Bretaña como de Francia por acabar con su ministerio; convirtiéndose en una condición 1719 cuando Felipe V ya busca finalizar con la guerra de la Cuádruple Alianza. Sallés Vilaseca (2016), 657.

49. Melchor de Macanaz después de su caída en desgracia en 1712 intentó mantener su servicio al monarca interviniendo en política internacional, sobrepasando de este modo sus atribuciones. De todos modos, su tarea política no fue relevante en sí misma y pocas veces fue requerido por el monarca, solo en una ocasión en Soissons (172628). Realmente, “the only concrete result of Macanaz's long exili [...] was his literary output”. KAMEN (1965), 711.

50. R. M. Alabrús Iglésias (2005-2006), 189. 
En segundo lugar, el grupo francés que conforma el partido español en Versalles con los duques de Maine a la cabeza junto con la princesa de Condé. Estos organizan y dan forma a la conspiración usando sus relaciones en la corte para llegar a sus objetivos. Por último, el príncipe de Cellamare quien ocupa una posición central y de intermediario entre París y Madrid, en tanto que embajador ordinario. Además de recabar información y cumplir con los objetivos principales, establece estas redes diplomáticas que facilitan dicha gestión, aunque sin mucho éxito.

\subsection{Las consecuencias políticas de la Conjura de Cellamare}

El fin de 1718 trajo consigo la declaración de guerra de Gran Bretaña a España, aunque ya se habían dado algunas escaramuzas ${ }^{51}$. Pocos días después, el 9 de enero de 1719 se publicaba una Ordenanza en París en la que Luis XV, o en su defecto Felipe de Orleans, se "veía obligado a declarar la Guerra al Rey de España" 52 en un conflicto en la práctica ya abierto: la guerra de la Cuádruple Alianza. En el mismo documento se especifican los motivos que llevan a tomar esta decisión; la problemática principal es la negativa de Felipe V a adherirse a los acuerdos de la Triple Alianza en 1717, aun así, se hace también referencia a la conjura de Cellamare. De hecho, este suceso le sirve al gobierno francés como pretexto para declarar la guerra incluyéndolo a la lista de agravios. Aun así, parece razonable pensar que, aunque se de más importancia a esta injerencia política, esta sea simplemente un motivo más que se suma a los principales: las empresas militares de Sicilia y Cerdeña que ponían en jaque la paz en Europa o, dicho de otra forma, la posición hegemónica de Francia.

La conjura de Cellamare es una herramienta útil para que la monarquía francesa pueda demostrar el riesgo existente en la política exterior española, aunque su posición en Madrid no distaba demasiado teniendo en cuenta el objetivo del embajador francés de debilitar la posición de Alberoni. Así pues, este recurso político no era más que un argumento de legitimación vacío que escondía los motivos reales de la declaración de guerra. Estos se pueden leer entre líneas en este fragmento de la misma ordenanza francesa:

51. La más relevante, la batalla del Cabo Passaro entre escuadras británicas y españolas el 11 de agosto de 1718.

52. AHN, ES, n. ${ }^{\circ} 2819$, fol. 1. 
como no podia asegurarse que el ministro del Rey de España moderase la ambición de sus proyectos y que no era justo que el reposo de la Europa dependiese de la obstinación, [...] se les han hecho de convenir [...] qué si alguno de los príncipes interesados rehusara consentir en la Paz, unirian sus fuerzas para obligarle a ello ${ }^{53}$.

Llama la atención como los distintos discursos de legitimación de ambas monarquías tienden a encontrarse en muchos puntos, aunque, a priori, partan de posturas contrapuestas. De hecho, lo que dista uno de otro suelen ser los argumentos básicos o los agravios que usan; Francia acusa a España de sus tentativas militares y su injerencia política culpabilizando a los ministros extranjeros. Por su parte, España acusa a Francia de no cumplir con su papel de potencia garante al no proteger los territorios italianos frente al Emperador ${ }^{54}$. Todos estos argumentos, a menudo engañosos y repletos de eufemismos, se basan en los tratados de Utrecht, por lo que deviene el eje de los discursos contrapuestos usándolos desde los propios intereses.

De este modo se llega a la guerra de la Cuádruple Alianza con muy poco alcance geográfico y, mucho menos, político. Tuvo un escenario principal en Italia, en la península Ibérica e incluso en Francia. Los enfrentamientos entre Francia y España se desarrollaron en dos epicentros básicamente. En primer lugar, la frontera entre estos dos estados; esto se explica a través de la preocupación por la fortificación de las plazas a lo largo del río Bidasoa, así como la necesidad de mandar hombres a ese punto, pero también en territorio catalán, donde hubo asedios en Roses o la Seu d’Urgell con el añadido de la presencia de guerrillas austracistas ${ }^{55}$. En segundo lugar, Felipe V prestó una débil ayuda a la conspiración del marqués de Pontcallec, una insurrección de la nobleza de Picardía, Bretaña y Poitou descontenta con el régimen de intendentes ${ }^{56}$. Este último foco demostraría las múltiples formas que podía tomar un conflicto bélico, aunque no fuese el espacio principal de este.

El fin del conflicto llegó con el tratado de la Haya que se firmó el 17 de febrero de 1720; aunque las conversaciones habían empezado en el verano del año anterior. En este se forzó a Felipe $\mathrm{V}$ a la adhesión al tratado de la Cuádruple Alianza lo que suponía “la renuncia [efectiva] de Felipe V a la

53. AHN, ES, n. ${ }^{\circ} 2819$.

54. En palabras de Felipe V: "asegurarme de los reinos de Sicilia y de Cerdeña”. BNE, 2/52217(10), fol. 11.

55. E. GimÉNEZ (2005), 596-597.

56. N. Sallés Vilaseca (2015), 303. 
corona de Francia y a los Estados de Italia”57, aunque se dejaba la puerta abierta en los casos de Toscana, Parma y Plasencia.

\section{CONCLUSIONES}

La conjura de Cellamare ha sido el objeto de estudio principal de este trabajo; aun así, se ha descrito un contexto mucho más complejo en el que pueden incluirse muchos aspectos, más o menos cercanos al mismo hecho. Es indiscutible que esta conjura no sirve de explicación para las relaciones franco-españolas de todo un lustro; pero es indiciativo de como estas fluctuaban y respondían a unos intereses particulares. De hecho, cada vez era más claro el alejamiento del dinasticismo, como base de las acciones del estado, hacia la imposición de unos objetivos más personalistas, tal y como define Bély en esta frase: "les intérêts héréditaires de la maison de Bourbon doivent ceder devant des réalités" ${ }^{2}$. No sólo se produce en los casos de Francia y España, sino que es extensible a otros estados europeos, traduciéndose en un nuevo panorama político en el que las relaciones eran mucho más endebles y dinámicas, buscando reiterativamente el equilibrio.

Esto explica, parcialmente, porqué se rechazaron de forma tan unánime las tentativas de Felipe V de recuperar el estatus perdido en Utrecht. Por otra parte, también se entiende por lo que suponía esto para la hegemonía de Gran Bretaña y Francia, así como para sus respectivas inestables situaciones internas. Aun así, la lectura que se hizo de estos intentos españoles fue tendenciosa culpabilizando a Alberoni directamente. Es innegable que este tenía un papel preponderante y una relación directa con los embajadores $^{59}$, como el mismo Cellamare, pero se debe tener en cuenta los propios intereses de los monarcas y de otros agentes que conformaban la monarquía.

El caso paradigmático es el de los territorios italianos perdidos en Utrecht; estos eran "los cimientos de la más inmediata y entrañable política exterior de España” y, la misma reina provenía de Parma. Al mismo tiempo, había "présence [...] de nobles italiens en Espagne et l'opinion de grands secteurs de sa cour qui sentaient comme une mutilation la perte de

\section{Ibidem, 314 .}

58. L. BÉLY (2007), 476.

59. Es indicativo de esto, la imposición de la vía reservada a partir de febrero de 1717 para los asuntos de estado; así como la estrecha relación que tenía con algunos embajadores como Cellamare, Beretti Landi o el marqués de San Felipe. N. Sallés Vilaseca (2016), 411-419. 
ces royaumes"60. Por lo tanto, es evidente que los intereses por recuperar esos territorios no provenían solamente de ese ministro, sino que tuvieron unos apoyos mucho más amplios y bajo unas aspiraciones que iban más allá de las posibles pretensiones de este cardenal.

Esta idea me es útil también para reflexionar en torno a la misma conjura de Cellamare y los personajes que intervinieron en ella. Una vez más, el gran culpable parecía ser Alberoni junto con el embajador español en Francia; el primero defenestrado en 1719 y el segundo al descubrirse la trama. Parece que el círculo francés queda olvidado y reducido a personajes secundarios que colaboran con Cellamare, pero lejos de esto parece más razonable pensar que las relaciones son multidireccionales y más simétricas de lo que parece. Se trata de hijos legitimados o nobles con un peso considerable en la corte de Versalles, por lo que su capacidad de influencia era importante.

Esto también se demuestra a través de la exhaustiva descripción que hace Felipe V a Cellamare y Patricio Laules de la corte de Versalles, habiendo vivido ahí durante muchos años. Que el monarca señalase a unos personajes en concreto evidencia el peso que tenían estos en ese ambiente, además de señalar la relevancia que tenía la información para los aspectos diplomáticos.

Del mismo modo, la misma organización de la conspiración no puede ser entendida solo desde Versalles, puesto que había unas redes más complejas que salían de París hacia Madrid o hacia Pau, donde residía el mismo Macanaz.

En definitiva, la conjura de Cellamare sirve para observar como se desarrollan las relaciones entre estados y el peso de los intereses particulares de cada monarquía, entendiendo su gobierno de forma amplia y no sólo en la figura del soberano. Como esto pasa por delante de los posibles vínculos sanguíneos convirtiendo el dinasticismo en un argumento de legitimación inserto en los discursos oficiales; aunque, este no deja de ser un elemento crucial para entender las relaciones entre estados europeos.

Por otro lado, este suceso se entiende como el clímax de distanciamiento entre ambas monarquías alargándose hasta el fin de la guerra de la Cuádruple Alianza, periodo que contrasta con el inmediatamente anterior y posterior. Esto demostraría estas fluctuaciones en los vínculos entre estas dos monarquías enmarcándolo en un periodo más amplio de entendimiento cordial en el que se dan acercamientos subrayables como alianzas matrimoniales

60. M. V. López-Cordón Cortezo (2003), 188. 
o Pactos de Familia (1733-1789), que pudieron ser otros mecanismos para desarrollar los propios intereses; evidenciando que los intereses hereditarios de los Borbón, ahora "doivent ceder devant des réalités"61. En la práctica, la conjura de Cellamare es un ejemplo paradigmático de ello.

\section{BIBLIOGRAFÍA}

Alabrús Iglésias, Rosa María (2005-2006), "El pensamiento político de Macanaz”, Espacio, tiempo y forma, Serie IV, Historia Moderna, 18-19, pp. 177-201. Albareda Salvadó, Joaquim (2007), "Proyectos políticos enfrentados en la "guerra más que civil” de 1705 a 1714", en A. Álvarez-Ossorio, B. J. García García y V. León SAnz (eds.), La pérdida de Europa. La guerra de Sucesión por la Monarquía de España, Fundación Carlos de Amberes, Madrid, pp. 271-292.

- (2015) «Los tratados de Utrecht-Rastatt y España», en J. Albareda Salvadó (Ed.), El declive de la Monarquía Hispánica y del Imperio Español. Los tratados de Utrecht (1713-14), Crítica, Barcelona, pp. 65-122.

Anderson, Matthew Smith (2014), The War of Austrian Succession, 1740-1748, Routledge, Londres-Nueva York.

Aparicio Valero, María Gloria (2013), Regalismo borbónico e historia crítica, Institució Alfons el Magnànim, Valencia.

Baudrillart, Alfred (2001), Felipe V y la corte de Francia, vol. 1, Universidad, Murcia.

BéLy, Lucien (2013), "Les négotiations franco-espagnoles pendant la Guerre de Succession d'Espagne”, Cuadernos de Historia Moderna, 12, pp. 61-76.

- (2007), L'art de la paix en Europe. Naissance de la diplomatie moderne XVIeXVIIIe siècle, Presses Universitaires de France, París.

- (2015) "El equilibro europeo, fundamento de la paz (1713-1725)", en J. AlbAReda Salvadó, (ed.), El declive de la Monarquía Hispánica y del Imperio Español. Los tratados de Utrecht (1713-14), Crítica, Barcelona, pp. 19-64. - (2007), "La diplomatie européenne et les partages de l'Empire espagnol”, en A. Álvarez-Ossorio, B. J. García García y V. León Sanz (eds.), La pérdida de Europa. La guerra de Sucesión por la Monarquía de España, Fundación Carlos de Amberes, Madrid, pp. 631-652.

Bernardo Ares, José Manuel de (2009), "Los embajadores franceses en España: Primeros ministros de la Monarquía Hispánica (1701-1709)”, en R. PorRes y I. Reguera (eds.), La proyección de la Monarquía Hispánica en Europa. Política, Guerra y Diplomacia entre los siglos XVI y XVIII, Universidad del País Vasco, Bilbao, pp. 121-146.

61. L. BÉLy (2007), 476.

(C) Baetica. Estudios Historia Moderna y Contemporánea, 38, 2018, 135-157.

Facultad de Filosofía y Letras, Universidad de Málaga. Departamento de Historia Moderna y Contemporánea 
Bernardo Ares, José Manuel de, Echeverría Pereda, Elena y Ortega Arjonilla, Emilio (2011), De Madrid a Versalles. La correspondencia bilingüe entre el rey Sol y Felipe V durante la Guerra de Sucesión, Ariel, Barcelona.

Bourgeois, Émile (1909), La diplomatie secrète au XVIIIe siècle: ses débuts, I. Le secrete du régent et la poltique de l'abbé Dubois (Triple et Quadruple Alliances) (1716-1718), Libraire Armand Colin, París.

EgIDo, Teófanes (1979), "El regalismo y las relaciones Iglesia-Estado en el siglo XVIII”, en R. García-Villoslada (ed.), Historia de la Iglesia en España, Biblioteca de Autores Cristianos, Madrid, pp. 125-254.

Giménez López, Enrique (2005), “Conflicto armado con Francia y la guerrilla austracista en Cataluña (1719-1720)”, Hispania, 65-220, pp. 543-600.

Kamen, Henry (1965), "Melchor de Macanaz and the foundations of Bourbon power in Spain”, The English Historical Review, 80 (317), 699-716.

López-Cordón Contezo, María Victoria (2003), "Pacte de familleo ou intérêts d’État? La monarchie française et la diplomatie espagnole du XVIIIe siècle”, en L. BÉLY (dir.), La présence des Bourbons en Europe, XVIe-XXIe siècle, Presses Universitaires de France, París, pp. 185-205.

Martínez Shaw, Carlos y Alfonso Mola, Marina (2001), Felipe V, Arlanza ediciones, Madrid.

Ozanam, Didier (2002), “Los embajadores españoles en Francia durante el reinado de Felipe V»” en J. L. Pereira Iglesias (ed.), Felipe V de Borbón (17011746). Actas del Congreso de San Fernando (Cádiz), de 27 de noviembre a 1 de diciembre de 2000, Universidad, Córdoba.

Sallés Vilaseca, Núria (2015), "La política exterior de Felipe V entre 1713 y 1719: un desafío al sistema de Utrecht”, en J. Albareda Salvadó (ed.), El declive de la Monarquía Hispánica y del Imperio Español. Los tratados de Utrecht (1713-14), Crítica, Barcelona, pp. 277-317.

- (2016), Giulio Alberoni y la dirección de la política exterior española después de los tratados de Utrecht (1715-1719). Tesis de doctorado bajo la dirección de J. Albareda Salvadó, Universitat Pompeu Fabra, Barcelona.

— (2016a), “«Que nos odien, si también nos temen». El razonamiento estratégico detrás de las campañas de Cerdeña y Sicilia (1717-1718)”, Vegueta, 16, pp. 313-334.

Saint-Simon, Louis de Rouvroy, duque de (2008), Saint-Simon en España. Memorias: junio de 1721-abril de 1722, Universidad, Alicante. Edición a cargo de M. Á. Pérez SAmper. 